\title{
Global epidemiology of canine rabies: past, present, and future prospects
}

\author{
This article was published in the following Dove Press journal: \\ Veterinary Medicine: Research and Reports \\ 5 November 2015 \\ Number of times this article has been viewed
}

\author{
Louise H Taylor \\ Louis $\mathrm{H} \mathrm{Nel}^{1,2}$ \\ 'Global Alliance for Rabies Control, \\ Manhattan, KS, USA; ${ }^{2}$ Department of \\ Microbiology and Plant Pathology, \\ Faculty of Natural and Agricultural \\ Sciences, University of Pretoria, \\ Pretoria, South Africa
}

\begin{abstract}
The rabies virus, a public health scourge from ancient times, is currently responsible for an estimated 59,000 human deaths a year, almost all transmitted via dog bites. It causes considerable economic impacts on developing countries, primarily in Africa and Asia, which can least afford these losses. However, despite its almost $100 \%$ case fatality rate, canine rabies is a completely preventable disease, and historic examples of canine rabies elimination in the developed world attest to this. Over the last decade, programs based on eliminating the source of the disease from dogs have shown success in reducing the public health burden of canine rabies in developing countries, notably across Latin America, and this has contributed to the growing evidence base necessary to change attitudes toward the feasibility of global canine rabies elimination. More recently, assessments of the current economic burden of canine rabies and the potential cost savings achievable through mass dog vaccinations have been added to this evidence base. Tools and support are available from the international community to help countries move progressively toward canine rabies elimination, and there is optimism that global freedom from canine rabies can be achieved within the next few decades.
\end{abstract}

Keywords: canine rabies, epidemiology, elimination, zoonosis, rabies virus

\section{Rabies virus}

The rabies virus (RABV, family Rhabdoviridae) is distributed globally, with only Antarctica and a few island territories considered RABV free. All mammals are susceptible to the virus, with reservoir species most notably among carnivores of the family Canidae. ${ }^{1}$ The virus is highly neurotropic, and once it enters the body through a break in the skin or mucous membrane, it migrates along the nerves from the site of infection to the brain where it causes fatal encephalitis. From the brain, the virus travels back out to the organs of the body, eventually causing them to shut down. ${ }^{2}$

Symptoms of rabies are variable, but some distinctive signs including severe anxiety, fear of water (hydrophobia), and fear of air (aerophobia) are recognizable in writings from millennia ago. ${ }^{3}$

During the final stages of disease, the virus is excreted in the saliva, and it is transmitted between hosts primarily through bites or scratches from infected animals, but more rarely transmission can occur through viral contact with mucous membranes. Although not all exposures result in symptomatic infections, once rabies symptoms develop, death almost invariably follows. In humans, extremely rare recoveries from clinical rabies have been documented, but these have almost always required intensive care and have not always resulted in complete recovery. ${ }^{4}$ 


\section{The public health threat}

RABV, classified as the type species in the genus Lyssavirus, family Rhabdoviridae, is the most important lyssavirus from a public health perspective. Thirteen other lyssaviruses can cause rabies, ${ }^{5}$ but only a few isolates of these viruses have been identified, and only five of them have ever been implicated in rare cases of human disease. ${ }^{1,6} \mathrm{By}$ far, the most significant public health threat comes from RABV, and over $99 \%$ of all globally reported human cases are caused by exposure to unvaccinated dogs infected with canine RABV variant, mostly in Asia and Africa. ${ }^{7}$ Spillover infections of canine rabies are associated with deaths in humans, ${ }^{8}$ economically relevant livestock (notably cattle, but also horses and goats ${ }^{910}$ ), and have threatened endangered carnivores such as the Ethiopian wolf and African wild dog (reviewed in Nel and Rupprecht ${ }^{11}$ ).

Rabies surveillance for both human and animal cases of rabies is inadequate to nonexistent in the regions of the world where the disease is most predominant, ${ }^{12}$ making a true assessment of the global burden of the disease difficult. However, the most recent and comprehensive model estimates that 59,000 human deaths due to canine rabies occur every year. ${ }^{8}$ RABV transmission maintained in wildlife reservoirs (notably mongooses, raccoons, foxes, skunks, and bats) can also cause human deaths, but because direct contact between humans and wildlife is much less common than that between humans and domestic animals, cases from these sources are relatively rare. It is probable that with better surveillance, and especially with control of canine rabies, the public health burden of wildlife-maintained rabies will become more apparent. ${ }^{13}$ However, evidence from regions where canine rabies is controlled or absent suggests that the scale of the problem will be orders of magnitude below the disease burden caused by canine rabies variants. ${ }^{14-16}$

\section{Rabies in ancient times}

Rabies has threatened man for millennia, with descriptions in ancient texts from the Mediterranean Basin ${ }^{17}$ to India, ${ }^{18}$ associating human disease with exposure to infected dogs. Large outbreaks of rabies in Europe and the Mediterranean Basin have been reported from the Middle Ages to the 20th century, with dogs and wolves the most frequently reported reservoirs. ${ }^{17}$ At the end of the 19th century, there was a drastic increase in canine rabies across Europe: a total of 1,112 people were reported to have died from rabies in England during the second half of the 19th century; in St Petersburg, 47 people died from rabies between 1863 and 1874; and in 1878, 500 cases of canine rabies and 24 human deaths were recorded in the city of Paris alone. ${ }^{17}$
There have been many bizarre methods falsely believed to cure or prevent rabies, including removing part of the tongue (the "worm") of dogs before they developed rabies, and feeding dogs chicken droppings or the root of the wild rose. ${ }^{3}$ Placing a dog's tongue in the shoe under the big toe was said to prevent rabies in humans, and a piece of hyena skin wrapped in cloth was reportedly a powerful prophylactic. However, if these failed, then a hydrophobic patient should be thrown into a pond, or lowered in a sack into a well until they had drunk enough water to overcome the hydrophobia. ${ }^{3}$

The earliest effective control measures against rabies were based on movement restrictions and muzzling of dogs, and the elimination of stray dogs. These methods were the backbone of the program that resulted in canine rabies elimination from the United Kingdom in 1902. ${ }^{17}$

\section{The era of vaccination}

With the development of Pasteur's first rabies vaccine in 1885 , the era of a much more efficacious means to control rabies began. Today, despite the almost $100 \%$ case fatality rate of human rabies, the disease is entirely preventable by preexposure and/or postexposure vaccination. While Pasteur and colleagues initiated private dog vaccinations in Paris, the first mass vaccination of dogs was in the early 1920s in Japan, constituting the first major national rabies control program. ${ }^{19}$ Oral vaccination of wildlife, first developed in the 1970s, has since been shown many times to effectively control the disease in key terrestrial hosts such as foxes, raccoons, and skunks. ${ }^{13}$ Sustained rabies vaccination of the reservoir animal population at a coverage rate of $70 \%$ or higher will eventually eliminate RABV from the reservoir species and prevent spillover into accidental hosts. ${ }^{20}$

Phylogenetic evidence indicates that lyssaviruses infected bats long before they infected terrestrial mammals, and most lyssaviruses, including RABV, still circulate in various bat species around the world. ${ }^{11}$ Effective methods to prevent RABV transmission among bats remain elusive however, ruling out the prospect of complete eradication of rabies at the present time. ${ }^{13}$ However, even after exposure to RABV from the bite of a rabies-infected mammal, safe and effective postexposure prophylaxis (PEP, incorporating wound washing, anti-rabies immunoglobulin, and anti-rabies vaccination) can protect an exposed person from developing rabies if the treatment is administered in a timely manner and according to the World Health Organization (WHO) recommendations. ${ }^{7}$

These two methods to prevent human deaths - one relying on human vaccination of exposed people, the other based on 
vaccination of sufficient numbers of dogs to break the cycle of transmission at the source - are the building blocks of a "one health" approach to canine rabies prevention and control. These two different means to prevent human deaths have been considered as separate alternatives: strategy A relying on PEP delivery to people and strategy $B$ relying on vaccination of dogs; or as components of a combined strategy A + B in analyses of the likely costs of alternative strategies. ${ }^{21}$

Countries such as Thailand achieved enormous success in preventing human deaths through the application of PEP, but also discovered the spiraling demand and consequent costs incurred by reliance on PEP alone. ${ }^{22}$ For example, compared to the situation in 1991, four times as many persons required PEP in 2003 (more than 400,000 persons). ${ }^{22}$ Recent data suggest that the People's Republic of China, which vaccinates 15 million people a year after potential rabies exposures, spends an estimated US\$650 million per year on human PEP alone. ${ }^{8}$

A far more sustainable approach is to prevent the spread of the infection at the source, in the animal population, while increasing access to PEP for exposed human patients when necessary. Where the political will and adequate finances are available to control canine rabies, deaths can and have been eliminated. Widespread application of canine vaccination has resulted in the elimination of canine rabies in several countries, including Malaysia in 1954, ${ }^{23}$ Japan in 1956, ${ }^{24}$ Taiwan in 1961, Singapore and notably across Western Europe (reviewed in Rupprecht et al, ${ }^{13}$ King et al, ${ }^{25}$ and Gongal and Wright ${ }^{26}$ ).

\section{Recent examples of success}

Enormous strides toward canine rabies elimination have been made across Latin America and the Caribbean, since the "Action Plan for the Elimination of Urban Rabies" was approved at the First Meeting of Directors of Animal Programs for Rabies Prevention and Control in Ecuador in $1983 .{ }^{16}$ Due to a massive coordinated canine vaccination program, confirmed rabies cases in dogs across the continent have decreased from approximately 25,000 in 1980 to less than 300 in 2010, and dog-transmitted human rabies deaths decreased from 350 to less than 10 during the same time period (Figure 1). Several countries, including Belize, Colombia, Costa Rica, Chile, Ecuador, Panama, Paraguay, and Uruguay, have reported no human or canine rabies cases for more than 10 years. ${ }^{16}$ Between 1990 and 2005, more than 150 million vaccine doses were administered in Mexico. Rabies cases in dogs decreased from 3,049 in 1990 to 70 cases in 2007, and human rabies cases due to dog-mediated rabies decreased from 60 in 1990 to 0 in $2000 .{ }^{27}$ In North America, molecular evidence was used to confirm the declaration that USA was free of canine rabies in $2007 .^{28}$

Progress has also been made recently in Asian and African countries. In Asia, an intersectoral rabies control program, based on two mass canine vaccination campaigns, succeeded in reducing human deaths and canine rabies cases to zero within 2 years on the island of Bohol in the Philippines. ${ }^{29}$ In Bali, Indonesia, two island-wide mass dog vaccination campaigns in 2010 and 2011 reduced the average number of rabid dogs reported each month from 45 to $6 .{ }^{30}$ An assessment of 4 years of improved rabies control intervention in Colombo City in Sri Lanka showed that the program had reduced dog rabies cases from an average of 43 per year in the period 2002-2005 to only two in the last 6 months of the intervention. ${ }^{31}$ Finally, in the Indian city of Jaipur, a combined vaccination and sterilization program between 1994 and 2002 decreased human deaths from the project area to zero, despite the population doubling over the course of the study and cases rising in other nearby areas. ${ }^{32}$ In Africa, a mass dog vaccination campaign in the Serengeti district of Tanzania resulted in a significant reduction in dog rabies incidence and a sharp decline in reported bites from suspected rabid dogs compared to control villages without dog vaccination. ${ }^{33}$

More recently, three demonstration programs coordinated by WHO and supported by the Bill and Melinda Gates Foundation (Philippines, Tanzania, and South Africa) have also shown significant progress. ${ }^{34}$ In the South Africa project in the province of KwaZulu Natal, a very clear correlation was shown between the falling number of animal and human cases, which have now been brought down to around 2 per month and 0 , respectively ${ }^{34}$ (Figure 1), and plans are in place to reach out across provincial and national borders to increase the zone of rabies control. In the Visayas Region of the Philippines, there were 9 suspected rabies cases in 2014 compared with the 43 cases in $2009 .{ }^{34}$ For the project site in South Eastern Tanzania, the average bite incidence decreased from 26/100,000 in 2011 to 12/100,000 in 2014 (with substantial differences between districts), which directly relates to lower PEP costs incurred by rabies exposures. ${ }^{34}$

\section{Current situation}

RABV is a highly opportunistic pathogen and canine rabies continues to spread to new areas, demonstrated by the last decade's epidemic across much of the People's Republic of China $^{35}$ and its emergence on previously rabies free islands such as Flores ${ }^{36}$ and Bali. ${ }^{30}$ Many rabies control programs have experienced setbacks, with pockets of unvaccinated 

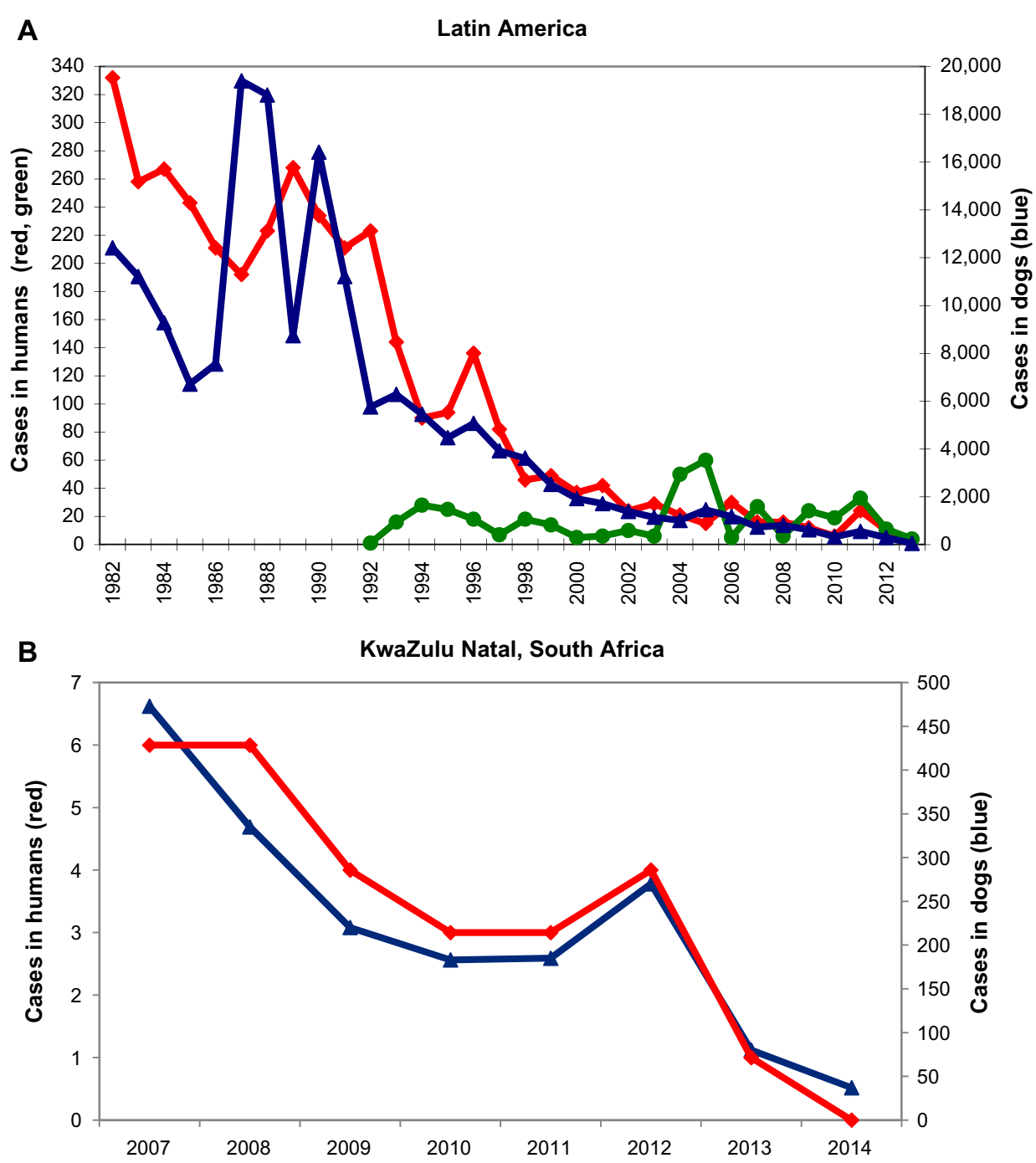

Figure I Rabies cases in humans and dogs for (A) Latin America 1982-20I3 and (B) KwaZulu Natal, South Africa 2007-20I4.

Notes: Red with diamonds, cases in humans from dogs; blue with triangles, cases in dogs; green with circles, cases in humans from bats. Graphs were drawn by the Pan American Health Organization with data from the SIEPI database. Reproduced with permission from Pan American Health Organization ${ }^{81}$ (A). Graph was redrawn from Figure 2 in theWHO/BMGF projects sixth meeting report. ${ }^{34}$ (B).Adapted from Pan American Health Organization. SIEPI Epidemiological Information System; 20 I5.Available from: http:// siepi.panaftosa.org.br/Panel.aspx?ldioma $=i ;{ }^{81}$ and from WHO/HTM/NTD/NZD/20 15.3. Report of the Sixth Meeting of the International Coordinating Group of the World Health Organization and the Bill and Melinda Gates Foundation Project on Eliminating Human and Dog Rabies. Geneva, Switzerland:WHO. Copyright 20I5. ${ }^{34}$

Abbreviations: BMGF, Bill and Melinda Gates Foundation; WHO, World Health Organization.

animals harboring cases that can spread rapidly if given a chance. Unless control measures are sustained and reentry or importation of new cases is prevented, the successes gained can be rapidly lost.

Therefore, despite the historical and more recent success in controlling rabies, rabies remains a neglected disease across many developing countries, particularly in Africa and Asia where victims of the disease come from the poorest sectors of society. ${ }^{6,37}$ As a disease of low priority, surveillance for rabies is woefully inadequate. In turn, the disease impact is not measured or appreciated, and evidence to support the increased spending required to control rabies in dogs remains absent. Given this cycle of neglect, it is not surprising that the best available estimates suggest that around 59,000 human deaths and 3.7 million disability-adjusted life years (DALYs) are lost each year due to canine rabies, and the cumulative cost of economic losses estimated to be over US\$8.6 billion every year. ${ }^{8}$ In a global context, the pattern of inequality is very marked, with the vast majority of the canine rabies burden falling on Africa and $\mathrm{Asia}^{8}$ (Figure 2).

\section{Costs and cost-effectiveness of control measures}

Attempts to build support for more widespread investment in rabies control require an appreciation of the current economic costs inflicted by rabies, the cost of control measures, and 

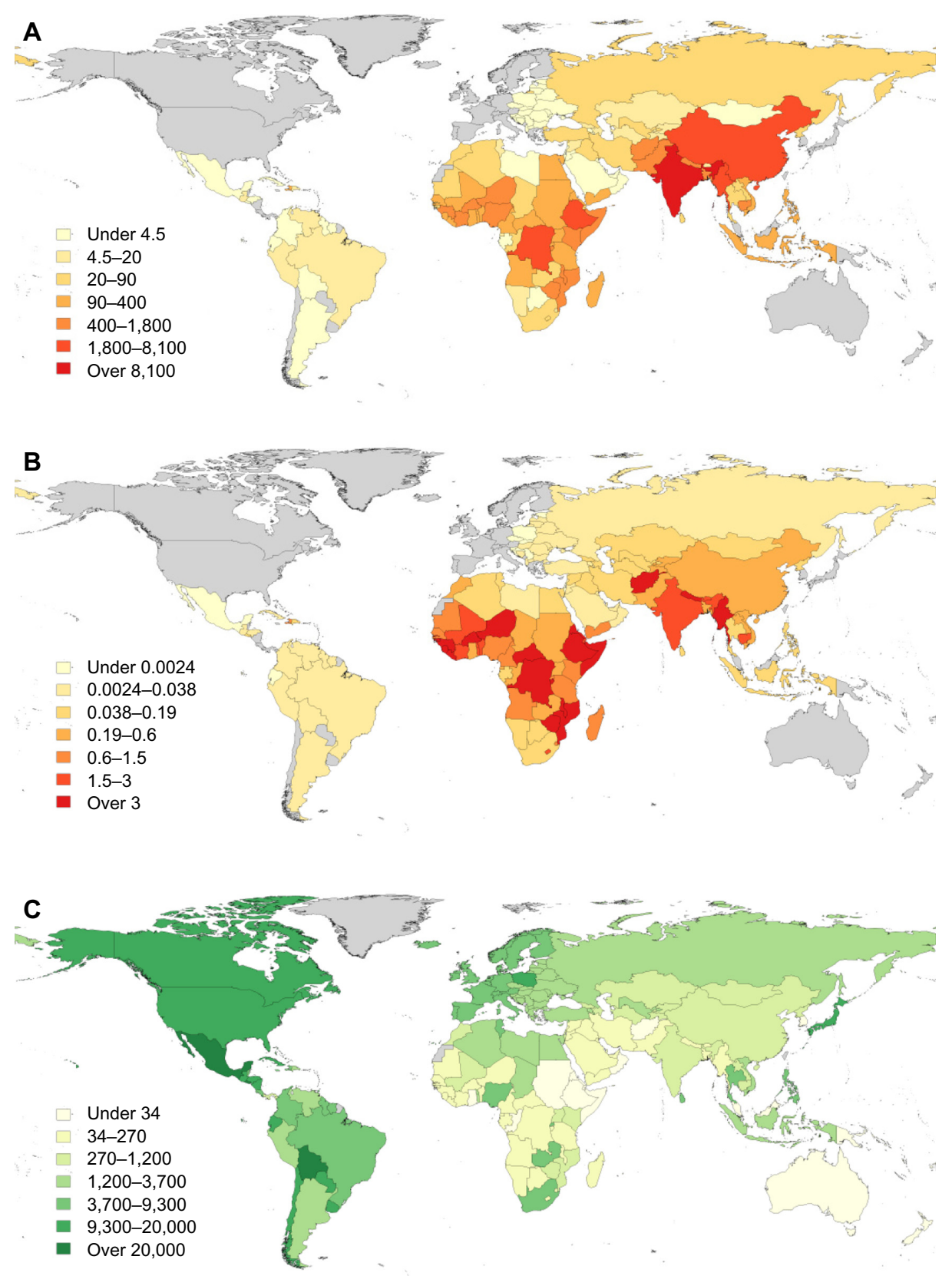

Figure 2 Distribution of the global burden of rabies estimated for 2010: (A) human rabies deaths, (B) per capita death rates (per 100,000 persons), and (C) expenditure on dog vaccination (US\$ per 100,000 persons).

Notes: Countries shaded in gray are free from canine rabies. Reproduced from Hampson K, Coudeville L, Lembo T, et al. Estimating the global burden of endemic canine rabies. PLoS Negl Trop Dis. 2015;9(4):e0003709. ${ }^{8}$

the potential benefits of those control measures. A body of recent work has started to address these issues.

The total cost of canine rabies to a country comprises a number of different aspects, including the direct costs of vaccinating animals and people, the indirect costs (often borne by the patients and dog owners) of lost salary and travel to seek vaccination, losses due to livestock that die of rabies, surveillance costs, dog population management costs, and productivity losses. This last category is often overlooked, but captures the economic value of the human lives lost to rabies, and with this comes a more realistic appreciation of the wider impact of rabies on a country. Productivity losses are the largest contributor to the total global financial impact of rabies and have recently been calculated by two divergent methods. Estimating productivity losses by multiplying the life years lost to rabies by the country-specific gross domestic product per capita produced a figure of $\$ 8.6$ million lost due to rabies globally per year. ${ }^{8}$ However, when the lives 
lost to rabies are valued using the value of a statistical life, these losses have been estimated at $\$ 124$ billion globally per year. ${ }^{38}$ The value of a statistical life is a measure used in economics, but only recently in public health, the latter reveals the economic value placed on a change in mortality risk, as derived from an analysis of how wages and spending are affected by mortality risk.

Taking data for each country from the recent global burden reassessment, ${ }^{8}$ it is possible to compare the pattern of burdens and costs across the three main endemic regions for canine rabies (Table 1 and Figure 3). Africa suffers the highest per capita rate of human deaths of the three continents. Death rates are lower in Asia, due to substantial investment in the provision of PEP, but overall deaths are higher. Finally, investment in dog vaccination in Africa and Asia is not high enough to create the level of coverage that has been shown to be effective at reducing rabies exposures in Latin America in recent years.

With an appreciation of the costs that rabies incurs on those countries least able to afford them (largely through lost productivity from those who have died, but also the costs of providing PEP and livestock losses among others), there is an anticipation that countries may be persuaded to increase investment in rabies control efforts.

Economic evaluations of a small number of recent mass vaccination campaign suggest that total programmatic costs to vaccinate each dog range from $\$ 1.18$ to $\$ 6.36$, and costs to provide one bite victim with PEP range from $\$ 54.88$ to $\$ 69.01^{39,40}$ (and references therein). In campaigns incorpo- rating both mass dog vaccination and PEP provision, costs in the veterinary sector for the dog vaccination component are often far lower than those in the health sector for provision of PEP. ${ }^{27,31,39,40,41}$ This is in line with the observed division of costs across Latin America, where canine rabies has been reduced so successfully that elimination appears to be within grasp $^{8}$ (Table 1 and Figure 3 ).

There is a strong logical argument that mass dog vaccination is a more cost-effective long-term strategy than relying on PEP provision alone. This argument hinges on the fact that tackling the disease in the source population (dogs) will lead to the protection of people, livestock, and other animals from canine-mediated rabies. ${ }^{42}$ If dog-mediated rabies is eliminated, the present costs of rabies (through premature deaths, livestock losses, and PEP provision) will translate into cost savings and benefits in terms of lives saved. ${ }^{43}$

The annual cost of rabies control through dog vaccination alone (strategy B) has been estimated to be $25 \%-56 \%$ that of a strategy relying on PEP alone (strategy A). ${ }^{21}$ Relying on dog vaccination alone is not ethically acceptable while rabies is still circulating, but there is potential for longer term cost savings by introducing dog vaccination into a combined strategy with PEP. Theoretical explorations of the cost and benefits of mass dog vaccination, over time horizons of $>10$ years are very compelling, and predictions have been made in general, ${ }^{21}$ and for specific settings in both Africa ${ }^{44,45}$ and Asia, ${ }^{46-48}$ all indicating considerable cost savings over the longer term with the use of mass dog vaccination in combination with PEP, compared to a strategy relying on PEP provision alone.

Table I The impacts and economic burdens of canine rabies vary by continent

\begin{tabular}{|c|c|c|c|}
\hline Impacts & Africa & Asia & Latin America \\
\hline Deaths & 21,502 & 37,266 & 182 \\
\hline Deaths/ 100,000 population & 2.09 & 0.93 & 0.03 \\
\hline DALYs lost & $\mathrm{I}, 345,643$ & $2,354,159$ & $|1,95|$ \\
\hline Exposures (to rabies, not all dog bites) & 847,326 & $14,633,844$ & $|22,70|$ \\
\hline PEP treatments & $\mathrm{I}, 387,848$ & $26,589,222$ & 835,656 \\
\hline Dog vaccination coverage & $\sim 14 \%$ & $\sim 16 \%$ & $\sim 60 \%$ \\
\hline Costs of prevention (US\$) & $15,948,303$ & $42,115,175$ & $63,287,263$ \\
\hline Dog vaccination & $14,520,789$ & $38,528,371$ & $6 I, 033,617$ \\
\hline Dog population management & $\mathrm{I}, 305,247$ & $3,369,953$ & $1,930,503$ \\
\hline Surveillance & 122,267 & 216,851 & 323,143 \\
\hline Preventable costs (US\$) & $1,266,514,109$ & $6,660,728,927$ & $289,466,942$ \\
\hline Productivity losses & $773,352,665$ & $3,852,276,021$ & $30,242,012$ \\
\hline Direct PEP & $156,110,495$ & $\mathrm{I}, 363,634,648$ & $|29,33|, 962$ \\
\hline Indirect PEP & $57,504,777$ & $\mathrm{I}, 225,773,035$ & $117,705,839$ \\
\hline Livestock losses & $279,546,173$ & $219,045,223$ & $12,187,129$ \\
\hline Total costs (US\$) & $1,282,462,4 \mid 2$ & $6,702,844,102$ & $352,754,205$ \\
\hline Costs of prevention/person & 0.02 & 0.01 & 0.12 \\
\hline Preventable costs/person & 1.23 & 1.67 & 0.54 \\
\hline
\end{tabular}

Notes: The bold data indicate total US\$ costs. Preventable costs are considered to be all those that would be eliminated with the global elimination of canine rabies. Data are derived from Hampson K, Coudeville L, Lembo T, et al. Estimating the global burden of endemic canine rabies. PLoS Negl Trop Dis. 20I5;9(4):e0003709.8

Abbreviations: DALYs, disability-adjusted life years; PEP, postexposure prophylaxis. 
African countries $\$ 1.28$ billion per year

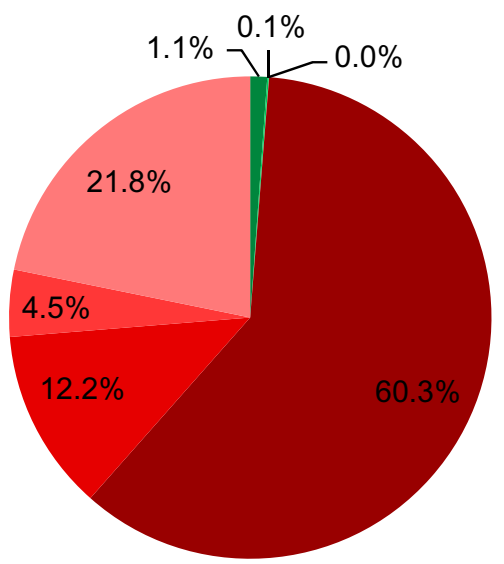

Asian countries $\$ 6.70$ billion per year

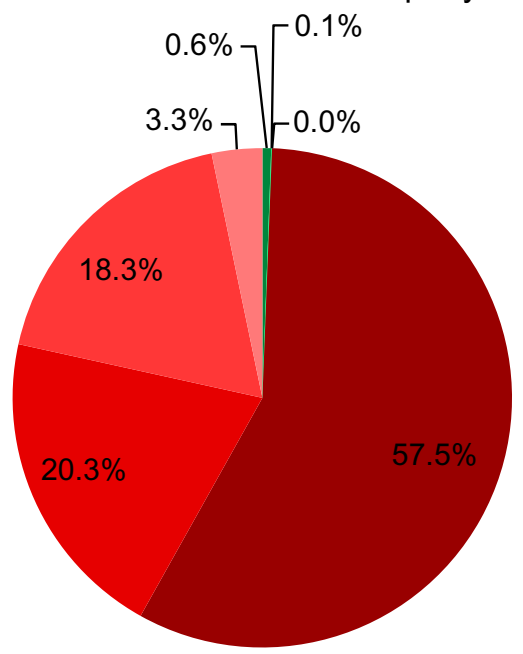

Dog vaccination

Dog population management

Surveillance

Productivity losses

Direct PEP

Indirect PEP

Livestock losses
Latin American countries $\$ 352.7$ million per year

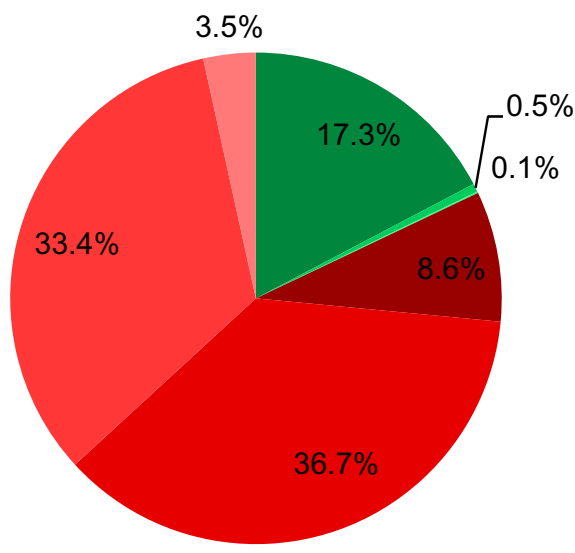

Figure 3 Spending on rabies prevention through mass dog vaccination and costs that would be saved with rabies elimination. Abbreviation: PEP, postexposure prophylaxis.

Significantly, one study suggests that mass dog vaccination combined with PEP is cost-effective even if elimination of canine rabies is not envisaged. ${ }^{45}$ A notable exception is that for Tamil Nadu, where predicted costs of scaling up current veterinary sector control methods to the whole state would be prohibitively expensive compared to providing PEP alone. ${ }^{49}$ However, these predictions are based on a state-wide vaccination and surgical sterilization campaign, known to be far more expensive than simpler vaccination-only campaigns.

Very little data on the cost-effectiveness of actual field campaigns are available. For the interventions where costs are available, the number of deaths potentially averted is very small and is susceptible to small fluctuations in human case numbers. For example, in the Colombo city study, although canine rabies cases fell significantly, the total number of human deaths for 4 years of the enhanced control intervention was three, the same as those that occurred in the 4 years prior to the intervention. ${ }^{31}$
The encouraging cost-effectiveness results from the theoretical models are based on their predictions that the PEP needs will be reduced as rabies incidence in dogs declines, ie, the number of people at risk of dying from rabies decreases as the number of bites that are from genuinely rabid dogs declines. A major problem is that PEP demand tends not to reduce quickly, and in fact can increase as a result of the awareness generated by control programs. PEP usage still remains high across Latin America, despite canine rabies incidences being extremely low, ${ }^{43}$ and PEP demand has risen rather than fallen during mass dog vaccination campaigns in Sri Lanka, Indonesia, and Philippines..$^{29,31,41}$ Provision of PEP to people bitten by a rabid animal should always be cost-effective, ${ }^{50}$ but the inability to target only those patients genuinely at risk is a major constraint with huge implications for the overall cost-effectiveness of campaigns.

A major complexity is that for a mixed intervention, the predictive models have only considered a single 
cost-effectiveness calculation. In fact, cost-effectiveness of the mass dog vaccination and PEP provision components should be viewed separately and dynamically, as they change over time and are not independent. As dog vaccination reduces the risk of a bite being from a rabid animal, the cost-effectiveness of providing PEP to everyone bitten falls dramatically, as very few are true exposures to rabies. ${ }^{51}$ The cost-effectiveness of continuing to vaccinate all dogs might be expected to fall too, but this is dependent upon the risk of rabies reintroduction. While reintroduction from other rabies endemic areas, or from rabies transmitted in wildlife populations is a significant risk, continued vaccination of dog populations will be warranted, and is likely to be highly cost-effective.

The judicious use of PEP (ie, identifying those few cases who really need PEP and targeting delivery there) becomes critical to maintaining high cost-effectiveness in PEP delivery where canine rabies is close to, or has been eliminated, and therefore to the cost-effectiveness considerations of the whole mixed intervention. Precise mechanisms to achieve this will vary from country to country and could benefit from improvement and better diagnostic tools. However, it is evident that an investment in good surveillance to build confidence that rabies has been eliminated (and no pockets of infection remain) is critical. ${ }^{52,53}$ The observation of biting dogs, as a deciding factor whether or not to continue with treatment, has an important role to play, ${ }^{54}$ and the clear identification of vaccinated dogs will be also be helpful. Rapid, simple rabies diagnostic tests suitable for use on samples from biting animals are still in development ${ }^{55,56}$ and will inevitably greatly contribute to the decision-making process and the optimal use of PEP when such tests have been shown to be reliable enough in this context. More complex and dynamic bioeconomic modeling systems would be beneficial to compare the impact on a program's cost-effectiveness of including these additional strategies to enable very targeted use of PEP.

\section{Aspirations for global canine rabies elimination: now is the time to act}

In a 1954 article in the Bulletin of the WHO, Dr KF Meyer reviewed the evidence for the control of rabies in humans by stating:

"Every international conference, regional meeting, or discussion on rabies has stressed, and continues to stress, that rabies must be eradicated from domestic dogs and that this is the most urgent, most challenging problem to be solved within the foreseeable future." 57

This advice was acted on in countries of Western Europe and the Americas, but across much of the developing world, chal- lenged with limited resources and numerous competing health priorities, there has been inertia for far too long. In fact, it was during the 1950s that colonial and postcolonial spread of rabies in many parts of Africa and Asia was at its most rampant. ${ }^{11}$

The last decade has seen some of the success of Europe and North America replicated in Africa and Asia, and the accumulated evidence has contributed to a change in the prospects for global canine rabies elimination.

Canine rabies is very clearly now a disease that most heavily impacts the poorest sectors of developing countries, yet the scale of the problem is beginning to be appreciated. With the calculation of economy-wide impacts of premature deaths of humans, livestock losses, and current spending on rabies prevention, there is a realization that the disease affects everyone in these countries, that the global inequality that this represents should not be tolerated, and that freedom from canine rabies should be considered a global public good. ${ }^{58}$ The major international health organizations are uniting to send a clear message that rabies elimination is feasible, and leading by example to ensure that the intersectoral collaboration required for rabies control is achieved. ${ }^{59}$

The basics elements of canine rabies control are clear:

1. the maintenance of a population of healthy, vaccinated dogs is the key defense for animals, people, and their livestock

2. the protection of humans potentially exposed to rabies needs to be ensured by timely and affordable access to PEP, until such time as the threat is mitigated. Under limited circumstances, this may require preexposure vaccination of those in high-risk areas at great distances from health services.

To achieve these objectives, supporting mechanisms are needed, including: 1) clear intersectoral collaboration to coordinate the provision of animal and human vaccination, 2) public awareness and community engagement to ensure dog vaccination coverage levels are reached and potentially exposed people know how to seek treatment, and 3) adequate surveillance to assess the need for and demonstrate progress in rabies control efforts.

An understanding of local dog ecology and the epidemiology of the canine rabies are highly relevant to designing effective rabies control. For example, a high dog population turnover can reduce herd immunity, ${ }^{60}$ human activity can be a strong factor in dog population characteristics and movements, ${ }^{61}$ and wildlife reservoir species, where present, may be an important consideration. ${ }^{62,63}$ The value of community consultation to ensure that control strategies are practical for the target populations is often underestimated, as this can provide vital information for the design of successful intervention strategies, as has been revealed by a number 
of recent knowledge, attitudes, and practices studies..$^{10,64,65}$ Some adaptation of methods to suit local settings will usually be needed, but the basic tenets of rabies control are well established, and tools to guide their application to particular settings are available to ensure effective programs. ${ }^{7,66}$

The recent project success stories provide an evidence base that canine rabies can be controlled, not just in theory, but also in practice in countries where this goal was perceived to be the most difficult to achieve. As evidence builds on the feasibility of canine rabies elimination in such countries, the myths that have so long contributed to the lack of progress are being dispelled. ${ }^{37,67}$ Dogs can be accessed for vaccination in sufficient numbers to allow vaccination targets and the required break in transmission to be achieved, ${ }^{61}$ rabies transmission in wildlife is not the major barrier it is often assumed, ${ }^{68}$ and even in resource-poor countries, success can be achieved with sustained efforts.

There is a growing appreciation that dog population management, once assumed to be a prerequisite for rabies control is a secondary issue, and only to be enacted when it is requested by the community. Contemporary research has shown that stray dogs are in fact rare and most so-called stray dogs are in fact free-roaming owned dogs. ${ }^{69}$ For far too long, ineffective mass culls have continued, destroying the critical community buy-in to rabies control programs and counterproductively resulting in increased immigration of unvaccinated dogs. Mass cullings of dogs without resort to vaccination is now universally condemned. ${ }^{7}$ Instead, vaccinating community dogs creates a population of dogs that can protect their communities from the threat of rabies. Where genuine unowned dogs are a major problem, and where dog owners request sterilization of their dogs, humane methods for sterilization (to be combined with vaccination) already exist, but better and less expensive tools, such as injectable immunocontraceptives, would benefit this effort. ${ }^{70}$

Tools such as the Canine Rabies Blueprint ${ }^{71}$ and associated Stepwise Approach towards Rabies Elimination ${ }^{72}$ have been developed as user-friendly online resources that guide countries to the information and support available and allow them to self-assess their progress toward canine rabies elimination. There is international support and training available from WHO collaborating centers, World Organisation for Animal Health (OIE) reference labs, Food and Agriculture Organization of the United Nations, the Pasteur Institute, animal welfare organizations, and many others. ${ }^{7}$ The recently implemented OIE canine rabies vaccine bank allows donors and countries to purchase high-quality vaccine in bulk at a discounted rate. ${ }^{73}$ Advocacy and community mobilization through World Rabies
Day activities ${ }^{74}$ and other initiatives can play a big part to increase community awareness and gain political ground.

The way forward needs to be sustainable. Catalytic funding will be required in many countries, but governments must step up and promise sustainability of control efforts and ensure that progress gained is not lost when external donors pull out.

Cross-border approaches, such as demonstrated across Latin America, are critical to expand rabies-free areas in a logical way. Regional collaborative groups allow countries to share their experience and learn from each other to build a coordinated approach. Such networks are well established in Asia and have recently been reinvigorated in $\mathrm{Africa}^{75}$ and the Middle East. ${ }^{76}$ Already, regional strategies exist for groups of countries in Asia, ${ }^{77,78}$ and national rabies elimination plans are beginning to be developed in Africa (eg, Kenya ${ }^{79}$ and Namibia $^{75}$ ). If international support and widespread use of guidance and assessment tools such as the Rabies Blueprint and Stepwise Approach towards Rabies Elimination can be channeled through these regional rabies networks, there is optimism that significant progress can be made toward rabies elimination in a short period of time. Rabies control success stories can be disseminated through such networks, and the lessons learned used to encourage others and refine the support tools to best fit the needs of individual countries, in this regional context. Ideally, areas where the goal of canine rabies control and elimination is reached should be maintained and expanded to subregional and eventually regional scales.

The new Sustainable Development Goals (SDGs) first discussed at the United Nations Conference on Sustainable Development in June 2012 will replace the Millennium Development Goals at the end of 2015. The SDGs recognize more explicitly than ever before the need to tackle inequity and provide health for all. ${ }^{80}$ With the support of international health organizations and their structures, global rabies experts, and the growing number of rabies champions in countries across Africa and Asia, there is a realization that canine rabies can and should be eliminated in all parts of the world. Achieving this global public good would be a very valuable contribution to achieving the SDGs by their target of 2030 .

\section{Acknowledgments}

We thank Deborah Briggs for very valuable comments on earlier drafts of this review. LHT is supported by funding from the UBS Optimus Foundation.

\section{Disclosure}

The authors report no conflicts of interest in this work. 


\section{References}

1. Hanlon C, Childs J. Epidemiology. In: Jackson AC, editor. Rabies: Scientific Basis of the Disease and its Management. 3rd ed. Waltham, MA: Academic Press; 2013:61-122.

2. Jackson AC. Human disease. In: Jackson AC, editor. Rabies: Scientific Basis of the disease and its management. 3rd ed. Waltham, MA: Academic Press; 2013:269-298.

3. Neville J. Rabies in the ancient world. In: King A, Fooks A, Aubert M, Wan-deler A, editors. Historical Perspective of Rabies in Europe and the Mediterranean Basin. A Testament to Rabies by Dr Arthur King. Paris, France: World Organisation for Animal Health; 2004:1-14.

4. Jackson AC. Recovery from rabies: a call to arms. J Neurol Sci. 2014; 339(1-2):5-7.

5. International Committee on Taxonomy of Viruses. Virus Taxonomy: 2014 Release; 2015. Available from: http://www.ictvonline.org/ virusTaxonomy.asp. Accessed June 29, 2015.

6. Nel LH. Factors impacting the control of rabies. Microbiol Spectr. 2013;1(2):OH-0006-2012.

7. WHO. WHO Expert Consultation on Rabies, Second Report. Geneva, Switzerland: World Health Organization; 2013.

8. Hampson K, Coudeville L, Lembo T, et al. Estimating the global burden of endemic canine rabies. PLoS Negl Trop Dis. 2015;9(4):e0003709.

9. Mondal SP, Yamage M. A retrospective study on the epidemiology of anthrax, foot and mouth disease, haemorrhagic septicaemia, peste des petits ruminants and rabies in Bangladesh, 2010-2012. PLoS One. 2014;9(8):e104435.

10. Jemberu WT, Molla W, Almaw G, Alemu S. Incidence of rabies in humans and domestic animals and people's awareness in North Gondar Zone, Ethiopia. PLoS Negl Trop Dis. 2013;7(5):e2216.

11. Nel LH, Rupprecht CE. Emergence of Lyssaviruses in the old world: the case of Africa. Curr Top Microbiol Immunol. 2007;315: 161-193.

12. Taylor LH, Knopf L; The Partners for Rabies Prevention. Surveillance of Human Rabies by National Authorities - a global survey. Zoonoses Public Health. Epub 2015 Feb 14.

13. Rupprecht CE, Barrett J, Briggs D, et al. Can rabies be eradicated? Dev Biol (Basel). 2008;131:95-121.

14. Rabies Bulletin Europe. Rabies Information System of the WHO Collaboration Centre for Rabies Surveillance and Research; 2014. Available from: http://www.who-rabies-bulletin.org/Queries/. Accessed June 29, 2015.

15. Dyer JL, Wallace R, Orciari L, Hightower D, Yager P, Blanton JD. Rabies surveillance in the United States during 2012. J Am Vet Med Assoc. 2013;243(6):805-815.

16. Vigilato MA, Clavijo A, Knobl T, et al. Progress towards eliminating canine rabies: policies and perspectives from Latin America and the Caribbean. Philos Trans R Soc Lond B Biol Sci. 2013;368(1623): 20120143

17. Blancou J. Rabies in Europe and the Mediterranean Basin: from antiquity to the 19th century. In: King A, Fooks A, Aubert M, Wandeler A, editors. Historical Perspective of Rabies in Europe and the Mediterranean Basin. A Testament to Rabies by Dr Arthur King. Paris, France: World Organisation for Animal Health; 2004:15-24.

18. Deshmukh R. Rabies. Pune, India: Yogaksema Department of Virology, Haffkine Institute; 2004.

19. Umeno S, Doi Y. A study on the anti-rabic inoculation of dogs and the results of its practical implication. Kitisato Arch Exp. Med. 1921;4:89-102.

20. Coleman PG, Dye C. Immunization coverage required to prevent outbreaks of dog rabies. Vaccine. 1996;14(3):185-186.

21. Bogel K, Meslin FX. Economics of human and canine rabies elimination: guidelines for programme orientation. Bull World Health Organ. 1990;68(3):281-291.

22. Hemachudha T. Rabies and dog population control in Thailand: success or failure? J Med Assoc Thai. 2005;88(1):120-123.

23. Wells CW. The control of rabies in Malaya through compulsory mass vaccination of dogs. Bull World Health Organ. 1954;10(5):731-742.
24. Shimada K. The last rabies outbreak in Japan. In: NaganoY, Davenport FM, editors. Rabies. Baltimore, MD: University Press; 1971:11-28.

25. King A, Fooks A, Aubert M, Wandeler A. Historical Perspective of Rabies in Europe and the Mediterranean Basin. A testament to rabies by Dr Arthur A King. Paris, France: World Organisation for Animal Health; 2004.

26. Gongal G, Wright AE. Human rabies in the WHO Southeast Asia region: forward steps for elimination. Adv Prev Med. Epub 2011 Sep 21.

27. Lucas CH, Pino FV, Baer G, et al. Rabies control in Mexico. Dev Biol (Basel). 2008;131:167-175.

28. Velasco-Villa A, Reeder SA, Orciari LA, et al. Enzootic rabies elimination from dogs and reemergence in wild terrestrial carnivores, United States. Emerg Infect Dis. 2008;14(12):1849-1854.

29. Lapiz S, Miranda M, Garcia R, et al. Implementation of an intersectoral program to eliminate human and canine rabies: the bohol rabies prevention and elimination project. PLoS Negl Trop Dis. 2012;6(12):e1891.

30. Putra AA, Hampson K, Girardi J, et al. Response to a rabies epidemic, Bali, Indonesia, 2008-2011. Emerg Infect Dis. 2013;19(4):648-651.

31. Hasler B, Hiby E, Gilbert W, Obeyesekere N, Bennani H, Rushton J. A one health framework for the evaluation of rabies control programmes: a case study from Colombo City, Sri Lanka. PLoS Negl Trop Dis. 2014;8(10):e3270.

32. Reece JF, Chawla SK. Control of rabies in Jaipur, India, by the sterilisation and vaccination of neighbourhood dogs. Vet Rec. 2006;159(12): 379-383.

33. Cleaveland S, Kaare M, Tiringa P, Mlengeya T, Barrat J. A dog rabies vaccination campaign in rural Africa: impact on the incidence of dog rabies and human dog-bite injuries. Vaccine. 2003;21(17-18):1965-1973.

34. WHO. Report of the Sixth Meeting of the International Coordinating Group of the World Health Organization and the Bill and Melinda Gates Foundation Project on Eliminating Human and Dog Rabies. WHO/HTM/NTD/NZD/2015.3. Geneva, Switzerland: WHO; 2015.

35. Guo D, Zhou H, Zou Y, et al. Geographical analysis of the distribution and spread of human rabies in china from 2005 to 2011. PLoS One. 2013;8(8):e72352.

36. Windiyaningsih C, Wilde H, Meslin FX, Suroso T, Widarso HS. The rabies epidemic on Flores Island, Indonesia (1998-2003). J Med Assoc Thai. 2004;87(11):1389-1393.

37. Lankester F, Hampson K, Lembo T, Palmer G, Taylor L, Cleaveland S. Infectious disease. Implementing Pasteur's vision for rabies elimination. Science. 2014;345(6204):1562-1564.

38. Anderson A, Shwiff SA. The cost of canine rabies on four continents. Transbound Emerg Dis. 2015;62(4):446-452.

39. Shwiff SA, Hatch B, Anderson A, et al. Towards canine rabies elimination in KwaZulu-Natal, South Africa: assessment of health economic data. Transbound Emerg Dis. Epub 2014 Nov 21.

40. Miranda LM, Miranda ME, Hatch B, Deray R, Shwiff S, Roces MC. Towards canine rabies elimination in Cebu, Philippines: assessment of health economic data. Transbound Emerg Dis. Epub 2015 Apr 17.

41. Wera E, Velthuis AG, Geong M, Hogeveen H. Costs of rabies control: an economic calculation method applied to Flores Island. PLoS One. 2013;8(12):e83654.

42. Cleaveland S, Kaare M, Knobel D, Laurenson MK. Canine vaccination - providing broader benefits for disease control. Vet Microbiol. 2006;117(1):43-50.

43. Shwiff S, Hampson K, Anderson A. Potential economic benefits of eliminating canine rabies. Antiviral Res. 2013;98(2):352-356.

44. Zinsstag J, Durr S, Penny MA, et al. Transmission dynamics and economics of rabies control in dogs and humans in an African city. Proc Natl Acad Sci U S A. 2009;106(35):14996-15001.

45. Fitzpatrick MC, Hampson K, Cleaveland S, et al. Cost-effectiveness of canine vaccination to prevent human rabies in rural Tanzania. Ann Intern Med. 2014;160(2):91-100.

46. Fishbein DB, Miranda NJ, Merrill P, et al. Rabies control in the Republic of the Philippines: benefits and costs of elimination. Vaccine. 1991; 9(8):581-587. 
47. Townsend SE, Sumantra IP, Pudjiatmoko, et al. Designing programs for eliminating canine rabies from islands: Bali, Indonesia as a case study. PLoS Negl Trop Dis. 2013;7(8):e2372.

48. Tenzin, Wangdi K, Ward MP. Human and animal rabies prevention and control cost in Bhutan, 2001-2008: the cost-benefit of dog rabies elimination. Vaccine. 2012;31(1):260-270

49. Abbas SS, Kakkar M, Rogawski ET; Roadmap to Combat Zoonoses in India Initiative. Costs analysis of a population level rabies control programme in Tamil Nadu, India. PLoS Negl Trop Dis. 2014;8(2): e2721.

50. Hampson K, Cleaveland S, Briggs D. Evaluation of cost-effective strategies for rabies post-exposure vaccination in low-income countries. PLoS Negl Trop Dis. 2011;5(3):e982.

51. Klepac P, Metcalf CJ, McLean AR, Hampson K. Towards the endgame and beyond: complexities and challenges for the elimination of infectious diseases. Philos Trans $R$ Soc Lond B Biol Sci. 2013;368(1623):20120137.

52. Banyard AC, Horton DL, Freuling C, Muller T, Fooks AR. Control and prevention of canine rabies: the need for building laboratory-based surveillance capacity. Antiviral Res. 2013;98(3):357-364.

53. Townsend SE, Lembo T, Cleaveland S, et al. Surveillance guidelines for disease elimination: a case study of canine rabies. Comp Immunol Microbiol Infect Dis. 2013;36(3):249-261.

54. WHO. Rabies vaccines: WHO position paper - recommendations. Vaccine. 2010;28(44):7140-7142.

55. Coetzer A, Sabeta CT, Markotter W, Rupprecht CE, Nel LH. Comparison of biotinylated monoclonal and polyclonal antibodies in an evaluation of a direct rapid immunohistochemical test for the routine diagnosis of rabies in southern Africa. PLoS Negl Trop Dis. 2014;8(9):e3189.

56. Markotter W, York D, Sabeta CT, et al. Evaluation of a rapid immunodiagnostic test kit for detection of African lyssaviruses from brain material. Onderstepoort J Vet Res. 2009;76(2):257-262.

57. Meyer KF. Can man be protected against rabies? Bull World Health Organ. 1954;10(5):845-866.

58. Zinsstag J. Towards a science of rabies elimination. Infect Dis Poverty. 2013;2(1):22.

59. FAO. FAO, OIE and WHO Unite for World Rabies Day to Call for Elimination of Disease. 2013. Available from: http://www.fao.org/ news/story/en/item/198087/icode/. Accessed June 29, 2015.

60. Gsell AS, Knobel DL, Kazwala RR, Vounatsou P, Zinsstag J. Domestic dog demographic structure and dynamics relevant to rabies control planning in urban areas in Africa: the case of Iringa, Tanzania. BMC Vet Res. 2012;8:236

61. Morters MK, McKinley TJ, Horton DL, et al. Achieving population-level immunity to rabies in free-roaming dogs in Africa and Asia. PLoS Negl Trop Dis. 2014;8(11):e3160.

62. Zulu GC, Sabeta CT, Nel LH. Molecular epidemiology of rabies: focus on domestic dogs (Canis familiaris) and black-backed jackals (Canis mesomelas) from northern South Africa. Virus Res. 2009; 140(1-2):71-78.

63. Wang L, Tang Q, Liang G. Rabies and rabies virus in wildlife in mainland China, 1990-2013. Int J Infect Dis. 2014;25:122-129.
64. Sambo M, Lembo T, Cleaveland S, et al. Knowledge, attitudes and practices (KAP) about rabies prevention and control: a community survey in Tanzania. PLoS Negl Trop Dis. 2014;8(12):e3310.

65. Prakash M, Bhatti VK, Venkatesh G. Rabies menace and control - an insight into knowledge, attitude and practices. Med J Armed Forces India. 2013;69(1):57-60.

66. Partners for Rabies Prevention. Blueprint for Canine Rabies Prevention and Control; 2010. Available from: http:/www.caninerabiesblueprint. org. Accessed June 29, 2015.

67. Lembo T, Hampson K, Kaare MT, et al. The feasibility of canine rabies elimination in Africa: dispelling doubts with data. PLoS Negl Trop Dis. 2010;4(2):e626.

68. Fitzpatrick MC, Hampson K, Cleaveland S, Meyers LA, Townsend JP, Galvani AP. Potential for rabies control through dog vaccination in wildlife-abundant communities of Tanzania. PLoS Negl Trop Dis. 2012;6(8):e1796.

69. Morters MK, McKinley TJ, Restif O, et al. The demography of freeroaming dog populations and applications to disease and population control. J Appl Ecol. 2014;51(4):1096-1106.

70. Munks MW. Progress in development of immunocontraceptive vaccines for permanent non-surgical sterilization of cats and dogs. Reprod Domest Anim. 2012;47(Suppl 4):223-227.

71. Partners for Rabies Prevention. Blueprint for Rabies Prevention and Control; 2010. Available from: http://www.rabiesblueprint.org Accessed June 29, 2015.

72. Partners for Rabies Prevention. The Stepwise Approach towards Rabies Elimination; 2014. Available from: http://caninerabiesblueprint.org/Astepwise-approach-to-planning. Accessed June 29, 2015.

73. OIE. Vaccine Bank for Rabies; 2013. Available from: http://www. rr-asia.oie.int/activities/sub-regional-programme/hped/vaccine-bankfmd-rabies/vaccine-bank-for-rabies/. Accessed September 08, 2015.

74. GARC. World Rabies Day; 2015. Available from: http://rabiesalliance. org/world-rabies-day/. Accessed June 29, 2015.

75. GARC. Pan-African Rabies Control Network Website; 2015. Available from: https://paracon.rabiesalliance.org/. Accessed June 29, 2015.

76. Fondation Mérieux. Middle East and Eastern Europe Rabies Expert Bureau Website; 2015. Available from: http://www.meereb.info/. Accessed June 29, 2015.

77. WHO SEARO. Strategic Framework for Elimination of Human Rabies Transmitted by Dogs in the South-East Asia Region. India: WHO; 2012.

78. ASEAN/OIE. The South-East Asia Dog Rabies Elimination Strategy. Jakarta, Indonesia: ASEAN/OIE; 2013.

79. Ministry of Health and Ministry of Agriculture Livestock and Fisheries. Strategic Plan for the Elimination of Human Rabies in Kenya 2014-2030; 2014. Available from: http://zdukenya.org/programme-1/. Accessed June 29, 2015.

80. United Nations. Sustainable Development Knowledge Platform; 2015. Available from: https://sustainabledevelopment.un.org/index.html. Accessed June 29, 2015.

81. Pan American Health Organization. SIEPI Epidemiological Information System; 2015. Available from: http://siepi.panaftosa.org.br/Panel aspx?Idioma=i. Accessed June 23, 2015.
Veterinary Medicine: Research and Reports

\section{Publish your work in this journal}

Veterinary Medicine: Research and Reports is an international, peer-reviewed, open access journal publishing original research, case reports, editorials, reviews and commentaries on all areas of veterinary medicine. The manuscript management system is completely online and includes a very quick and fair peer-review system.

\section{Dovepress}

Visit http://www.dovepress.com/testimonials.php to read real quotes from published authors. 